\title{
Corrigendum: Carrier generation and electronic properties of a single-component pure
} organic metal

Yuka Kobayashi, Takeshi Terauchi, Satoshi Sumi and Yoshitaka Matsushita

Nature Materials 16, 109-114 (2017); published online 10 October 2016; corrected after print 9 August 2017

In the version of this Article originally published, the sign of each $x$-axis value in Fig. $2 \mathrm{~d}$ and its inset was incorrect. This has been corrected in the online version and the correct panel is shown here. This change does not affect the results of the paper.

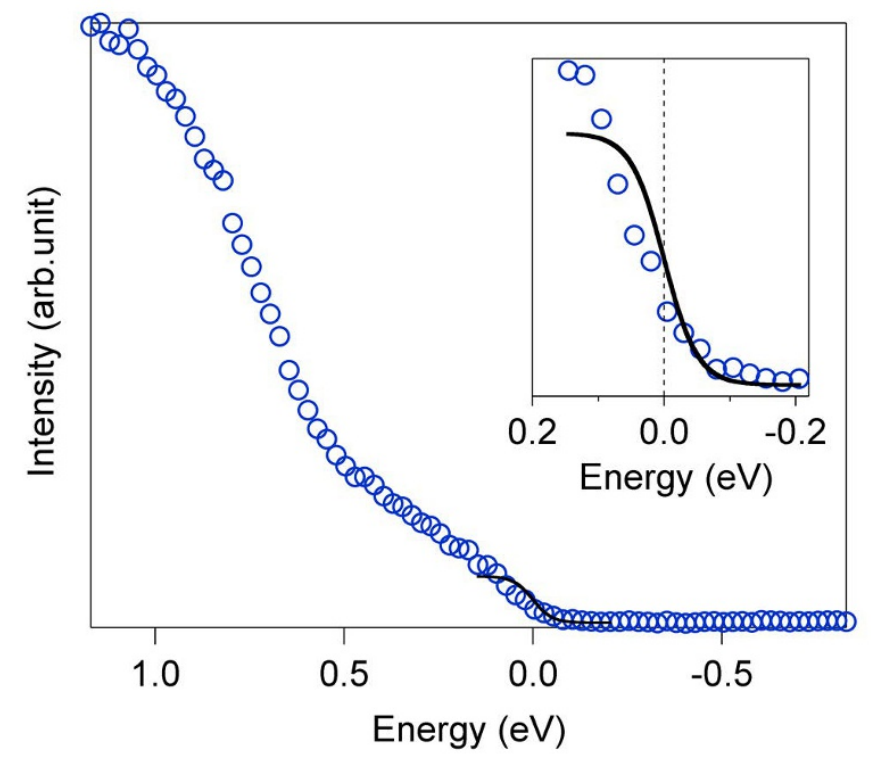

